\title{
Analysis of Reinforced Concrete Framed Structure Subjected to Blast Load using Sap2000
}

\author{
Mittakolu Harveen Sai \\ PG Scholar, CVR College of Engineering/Civil Engg. Department, Hyderabad, India \\ Email: mail.harveen@gmail.com
}

\begin{abstract}
Blast is a wave of exceedingly compressed air spreading outwards from an explosion. Blast loading is the result of an explosion where this refers to a fast and surprising launch of saved energy. Some portion of the energy is released as thermal radiation while the major component of the response is coupled into the air as air blast and into the dirt as ground stun, both as radially growing stun waves. Blast loading on buildings can be from unconfined or partially restrained explosion charges. In the present project, the main aim is to analyze the response of reinforced concrete framed structure subjected to blast loads, with external blasting stand-off distances as $10 \mathrm{~m}, 20 \mathrm{~m}, \& 30 \mathrm{~m}$ and with different charge weights as $100 \mathrm{~kg}, 200 \mathrm{~kg}$, and $300 \mathrm{~kg}$ TNT. shear wall techniques are implemented to resist the structure using IS 4991:1968. Dynamic analysis of framed structure is done by time history function method using SAP2000 software and it also includes the detail report on displacements, and story drift of structure.
\end{abstract}

Index Terms: Explosion, impact, air blast, structural response, stand-off distances, SAP2000.

\section{INTRODUCTION}

Blast loading is a rising threat in the world, due to an extend in global terrorism. This creates an increased danger to critical infrastructure due to blast load. The cost of building was upgrading for a "certain level" of resistance against terrorist threats. A blast explosion is immediately cause of nearby building in a catastrophic damage. Due to main fiascoes following from gas-chemical blasts outcome in enormous unique burdens, bigger than the first sketch heaps of structure by way of this building's outside and inside underlying casings, falling of dividers, extinguishing of goliath regions of windows, and closing down of fundamental life security frameworks such as fire, \& smoke induced damage to structure. blast induced the impulsive loads by these loads considerations the structure can be analyzed and designed with in Indian standard limits. [8]

\section{A. Objective:}

1. A $\mathrm{G}+10$ multistore commercial structure within IS 456:2000 limits for section properties and IS 10262:2009 limits for concrete mix design.

2. Gravity loads are induced on structure within the Indian standards limits.

3. By numerical calculation with respect to IS 4991:1968 blast load is applied to structure.

4. With the same intensity of blast and shear wall technique are used.

5. Time history function is used to analyze with blast load.

\section{B. Scope:}

In order to achieve the above objectives, tasks involving computations were carried. Reinforced concrete framed structure is subjected to bast dynamic loads in FEM package SAP2000 and the effect of blast pressure on structural components was represented.

\section{BACKGROUND}

\section{A. Explosion:}

It is an abrupt transformation of potential energy into kinetic energy with creation of gas discharge under pressure condition. Due to sudden release of gas pressure causes an increase in temperature and material present in that pressure is converted into hot compressed gases. These gases are in high temperature and high pressure and expand rapidly without a unique direction that creates a pressure wave which is known as a shock wave. The shock wave is air is generally referred as blast wave and almost instantaneously damage the built environment.[14]

i. In Chemical Explosion: Fuel or any other carbon and hydrogen atoms mixes with air or another oxidizer agent results in rapid combustion reactions and gets damage to structures and environmental creatures [3]

ii. In Physical Explosion: Energy is launched from the catastrophic failure of a compressed gasoline in cylinder, volcanic eruptions and mixing of two liquids at one-of-a-kind temperatures [3]

iii. In Nuclear Explosion: Materials used to produce nuclear explosion by fission contains isotopes of uranium and plutonium and materials used to produce nuclear explosion. [3]

\section{B. Blast phenomenon:}

When the blast occurs with respect to stand off distance to structure, there is an increase in pressure above the ambient atmospheric pressure $\left(\mathrm{P}_{\mathrm{o}}\right)$. the pressure rapidly increases and reaches its peak value called over pressure $\left(\mathrm{P}_{\mathrm{so}}\right)$. The pressure at that point rots into the surrounding level at time $\left(t_{d}\right)$. After a session, the explosion at a certain distance the pressure behind the shock front decreases at that stage is called Negative Phase/ Negative phase impulse. The time duration runs in negative phase impulse is called negative duration $\left(t_{d}{ }^{-}\right)$. Later the pressure behind the shock front increases at that stage is called Positive Phase/ Positive phase impulse. The time duration runs in positive phase impulse is called Positive duration $\left(t_{d}\right)$ as shown in Figure 2.1. [7] 


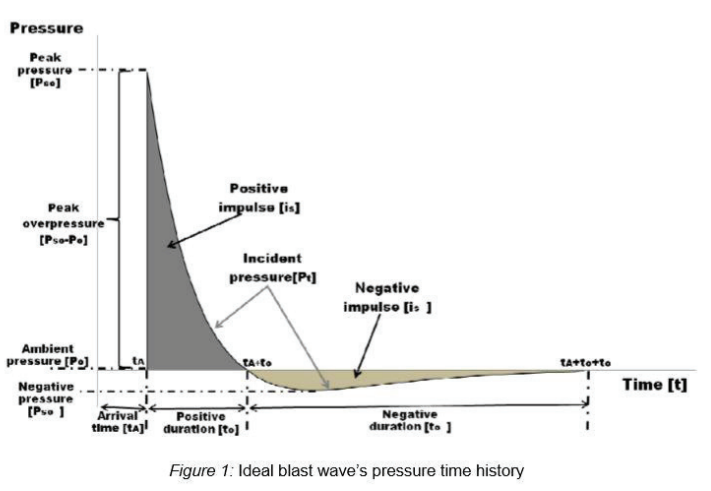

Figure 2.1. Blast Wave and Amplitude-Frequency Relations [12]

\section{LITERATURE SURVEY}

SURAJ D BHOSALE, SHRINIVAS. R. SURVANSHI [2] In this paper structural dimensions are calculated step by step process such as actual distance and scaled distance as per scaling law. Explosion parameters are determined using (IS 4991-1968) Analysis of explosive effect on building in STADD-pro software. Dynamic analysis of buildings is done by time history function method by using IS code 4991-1968.

P. SRINIVASA RAO, P. MANOJ KUMAR, G. TIRUPATHI NAIDU [3] In this paper behaviour of multistoreyed building of $\mathrm{G}+7$ is exposed to $100 \mathrm{~kg}$ TNT blast material with shifted distances occurred as $10 \mathrm{~m}, 20 \mathrm{~m}, 30 \mathrm{~m}$, and $40 \mathrm{~m}$ far away from the structure. By utilizing IS code 4991-1968, Blast boundaries are determined physically and executed in STADD-ace apparatus. The outcomes acquired from Blast loads on structure are looked at in static condition and upgraded the structure opposed to impact loads.

ASHISH KUMAR TIWARI [5] In this paper a steel frame building was subjected to blast loading is analysed by using two different software tools as SAP2000 and FEM package ANSYS AUTODYN. By calculating examined blast load manually using and applied on joints. By different charge weights and at different standoff distance steel columns subjected to an amount of blast pressure structural response Dynamic response of steel structure and concrete structure was examined in impact of blast loading using Finite Element package Ansys is modelled and then analysed in Autodyn.

KANCHAN PUJARI, PROF. D.H. TUPE, PROF. DR. G.R. GANDHE [11] In this paper 0.1 tonne of TNT explosion is considered and blast load is applied to $\mathrm{G}+10$ rectangular concrete structure with and without shear walls with a stand-off distance $30 \mathrm{~m}$. The blast loads are numerically determined by using IS code 4991-1968, blast phenomena and blast parameters were defined. Serial blast parameters which are extracted from IS code 4991-1968 considering only positive phase pressures Non-Linear Time history function has been performed using Finite element program SAP-2000. RCC Structure in filled with shear walls and analysed similarly.

A. LALITHA, V. LAKSHMI [10] In this paper a $\mathrm{G}+5$ multi-story RCC building represents the effect of blast load with a charge weight of $100 \mathrm{~kg}$ Trinitrotoluene (TNT) within stand-off distance $40 \mathrm{~m}$ away from the structure. Impact powers can cause loss of underlying trustworthiness because of halfway or complete breakdown of primary individuals. impact loads are dynamic load calculated by numerically as per Indian standards 4991-1968 and by using this blast parameters time history force analysis is performed in STADD-pro software tool. And similarly, the G+5 multistory RCC building is analysed in static conditions. Results from dynamic and static condition were compared: peak lateral displacements, velocity, acceleration by revision in design in static condition, resist the effect of blast forces.

\section{Finite element Alalysis Software}

SAP2000 is a structural engineering software product developed by csiamerica. That caters the design and analysis of any type of structure. Basic and advanced, ranging from 2D to $3 \mathrm{D}$ frame structure is modelled tools and templates, code-based load prescriptions, evaluation techniques and solution techniques, all coordinate with the grid like geometry unique to this class of structure. modelled, analyzed, designed, and optimized of structure was evaluated at different environmental conditions and streamlines of engineering process. In addition, advanced features are available as non-linear dynamic analysis and customizable output reports across all coordinates in sap 2000 useful for professional practices. Design and Output is fully integrated with the analysis process in SAP2000 designing reinforcedconcrete sections, and steel sections are checked automatically. It can robotically generate reviews for the presentation of pictures and data through the usage of Finalized member design, deformed geometry per load combination or mode shape, moment, shear, and axial-force diagrams, section-cut response displays, and animation of time-dependent displacements define a few of the pictures on hand upon conclusion of analysis. [5]

\section{Analytical Study}

Blast loading is the short duration load also called impulsive loading. When this high-pressure shock front strikes from a surface at an angle, it is reflected by producing an increase in pressure of air. Reflected pressure varies with the angle of incidence dependent on incident pressure. Duration of the blast shock by front is of the order of milliseconds. [2]

System development by considering G+10 storied RCC structure. Modelling of RCC structure was developed in finite element software program SAP2000. Material specifications, structural properties and section properties with respect to Indian standard limits. 


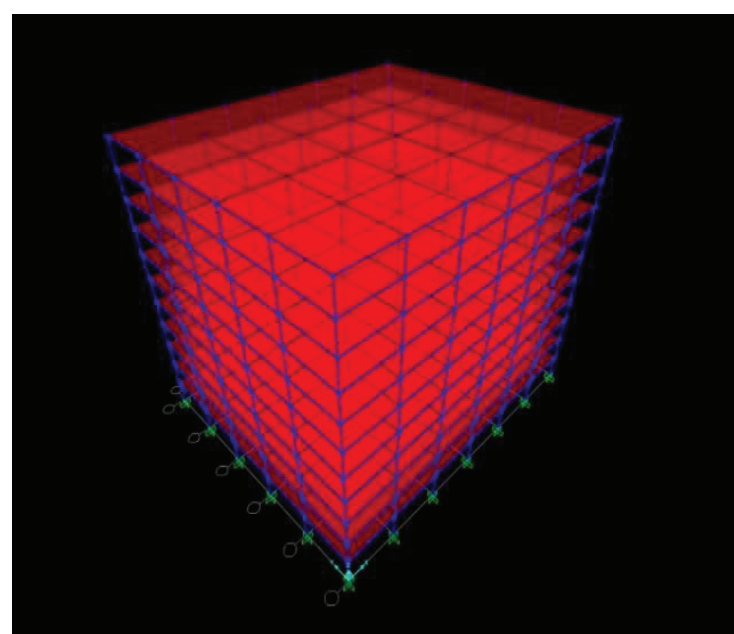

Figure 5.1. $\mathrm{G}+10$ building in 3D view

Gravity loads are the vertical direction forces that act on a structure. The intensity of dead load was composed of selfweight of members that is columns, beams, slabs and infillwalls. Based upon gravitational direction.

TABLE I.

GRAVITY LOADS IMPOSED ON STRUCTURE

\begin{tabular}{|l|l|l|}
\hline Name of load & $\begin{array}{l}\text { Load imposed on } \\
\text { structure }\end{array}$ & Type of load \\
\hline $\begin{array}{l}\text { Live load } \\
\text { Super dead } \\
\text { load }\end{array}$ & $2 \mathrm{kN} / \mathrm{m}^{2}$ & $\begin{array}{l}\text { Area load } \\
\text { Area load }\end{array}$ \\
$\begin{array}{l}\text { External wall } \\
\text { load }\end{array}$ & $11.4816 \mathrm{kN} / \mathrm{m}^{2}$ & Frame load \\
$\begin{array}{l}\text { Internal wall } \\
\text { load } \\
\text { parapet wall } \\
\text { load }\end{array}$ & $5.705 \mathrm{kN} / \mathrm{m}^{2}$ & Frame load \\
\hline
\end{tabular}

\section{A. Calculation of external blast load:}

A G+10 storey RCC commercial building is subjected to $100 \mathrm{~kg}$ Tri nitro toluene (TNT) blast source at stand-off distance $10 \mathrm{~m}$ away from the structure at the ground level was considered, imported into the finite element software SAP2000 with material specifications, structural properties, and gravity loads.

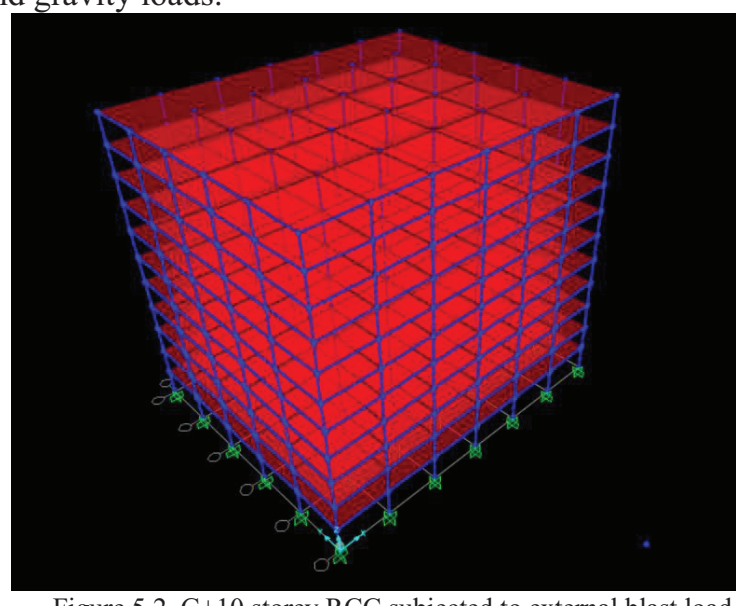

Figure 5.2. G+10 storey RCC subjected to external blast load

\section{B. Calculation for actual distance:}

Actual distance is where the distance between blast intense takes place and every beam column joint present in the exposed frame is calculated using coordinates represented in finite element software SAP2000. Coordinates at blast intensity takes place are $\left(\mathrm{x}_{1}, \mathrm{y}_{1}, \mathrm{z}_{1}\right)$ and beam column joint which are exposed are $\left(\mathrm{x}_{2}, \mathrm{y}_{2}, \mathrm{z}_{2}\right)$.

$$
\sqrt{\left(\left(\mathrm{X}_{2}-\mathrm{X}_{1}\right)^{2}+\left(\mathrm{Y}_{2}-\mathrm{Y}_{1}\right)^{2}+\left(\mathrm{Z}_{2}-\mathrm{Z}_{1}\right)^{2}\right)}
$$

\section{Calculation for scaled distance:}

The distance of the explosion points from the structure of interest in Critical boundaries for impact stacking. The pinnacle pressure worth and speed of the impact wave decline quickly by expanding the distance between the impact source and the objective surface, effect of distance on the impact attributes can be considered with the guide of the presentation of scaling laws. These scaling laws can scale impact boundaries.

As per Indian standard 4991:1968 clause 5.3

Scaled distance $\mathrm{x}=$ Actual distance $/ \mathrm{W}^{1 / 3}$ $\mathrm{W}=$ yield of blast in comparable weight of the reference explosive estimated in tonnes.

\section{Calculation for blast parameters.}

When a blast takes place on a ground burst of 1 tonne explosive with respect to scaled distance. Blast parameters are such as

$\begin{array}{ll}\text { peak side on over pressure ratio } & \mathrm{p}_{\mathrm{so}} / \mathrm{p}_{\mathrm{a}} \\ \text { Mach no } & \mathrm{M} \\ \text { Positive stage span } & \mathrm{t}_{\mathrm{o}} \\ \text { Span of identical three-sided pulse } & \mathrm{t}_{\mathrm{d}} \\ \text { Dynamic pressure ratio } & \mathrm{q}_{\mathrm{o}} / \mathrm{p}_{\mathrm{a}} \\ \text { Peak reflected overpressure - ratio } & \mathrm{P}_{\mathrm{ro}} / \mathrm{p}_{\mathrm{a}}\end{array}$

Blast parameters are interpolated using every beam column joint calculated scaled distance. Blast parameters are given in IS 4991: 1968 Table 1.

\section{E. Calculation for exposed area:}

Exposed area is calculated by using a beam column joint. Exposed area is covered every equal distance at every beam column joint in four directions. When the beam column joint is at the corner edge of structure i.e., exposed area is covered equal distance as shown in Figure 5.3.
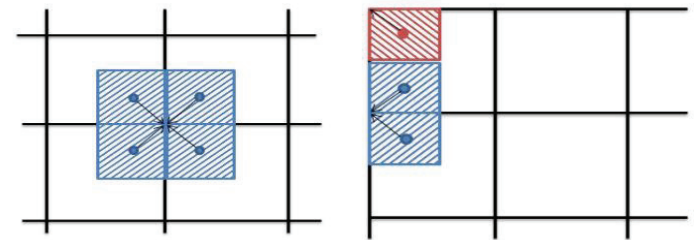

Figure 5.3. Distribution of blast pressure from wall to beam column joint

\section{F. Calculation for blast force:}

Peak reflected overpressure ratio (Pro/pa) where pa is the ambient atmospheric pressure. $\mathrm{Pa}$ is $1 \mathrm{~kg} / \mathrm{cm} 2$ the value of $\mathrm{p}_{\mathrm{ro}}$ is given in above Peak reflected overpressure is in $\mathrm{kg} / \mathrm{cm} 2$ converted into kilonewton. By multiplying exposed area with peak reflected overpressure i.e., we get blast force.

The blast load / blast force is applied with respect to the beam column joint. By applying blast load/ blast force on beam column joint design Rule's setup in finite element software SAP2000 we get detailed report in displacement, story drift and of RCC structure. 
Similarly, blast load/ blast force is calculated for $20 \mathrm{~m}$ and $30 \mathrm{~m}$ stand-off distance at charge weight of $100 \mathrm{~kg}$ TNT.

Similarly, blast load/ blast force is calculated for $10 \mathrm{~m}, 20 \mathrm{~m}$ and $30 \mathrm{~m}$ stand-off distance at different charge weights of $200 \mathrm{~kg}, 300 \mathrm{Kg}$ TNT

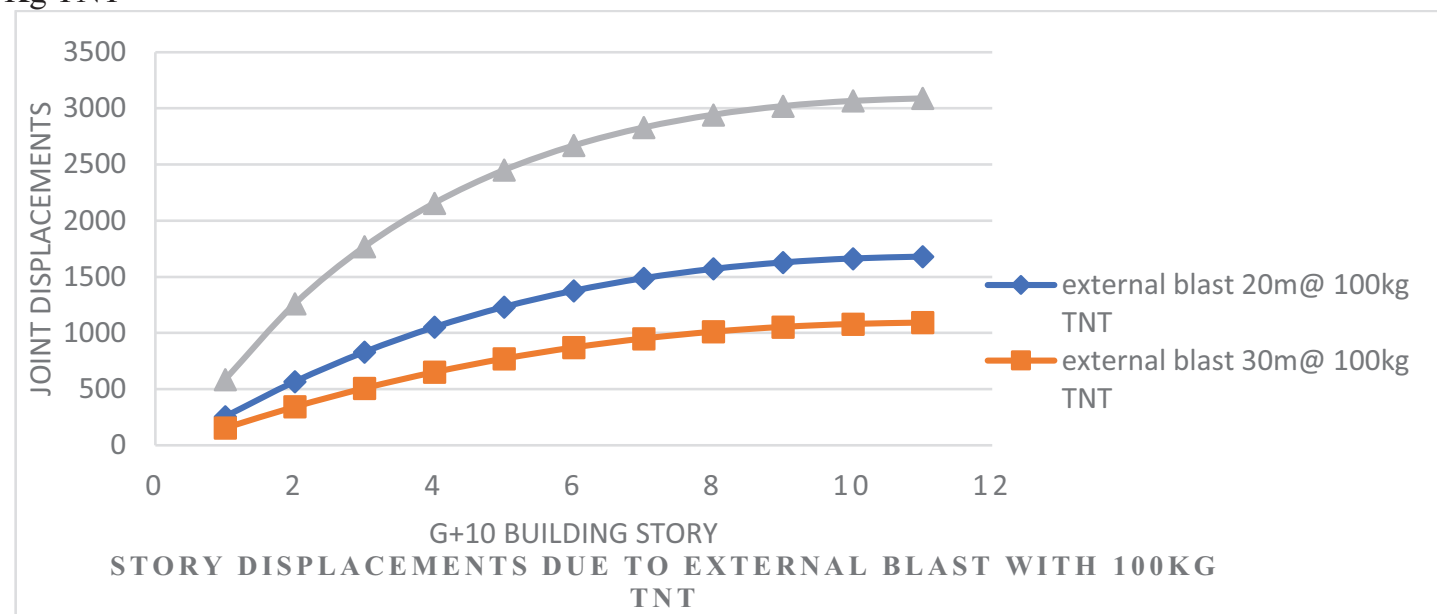

Figure 5.4. Combined graphs charts of storey displacements in UY - direction in external blast charge weight of $100 \mathrm{Kg}$ TNT with different standoff distances

As shown in Figure 5.4, framed structure variations of displacement (units: $\mathrm{mm}$ ) graphs with respect to storey height at different stand-off distance as $10 \mathrm{~m}, 20 \mathrm{~m}$ and $30 \mathrm{~m}$ in external blast charge weight of $100 \mathrm{Kg}$ TNT

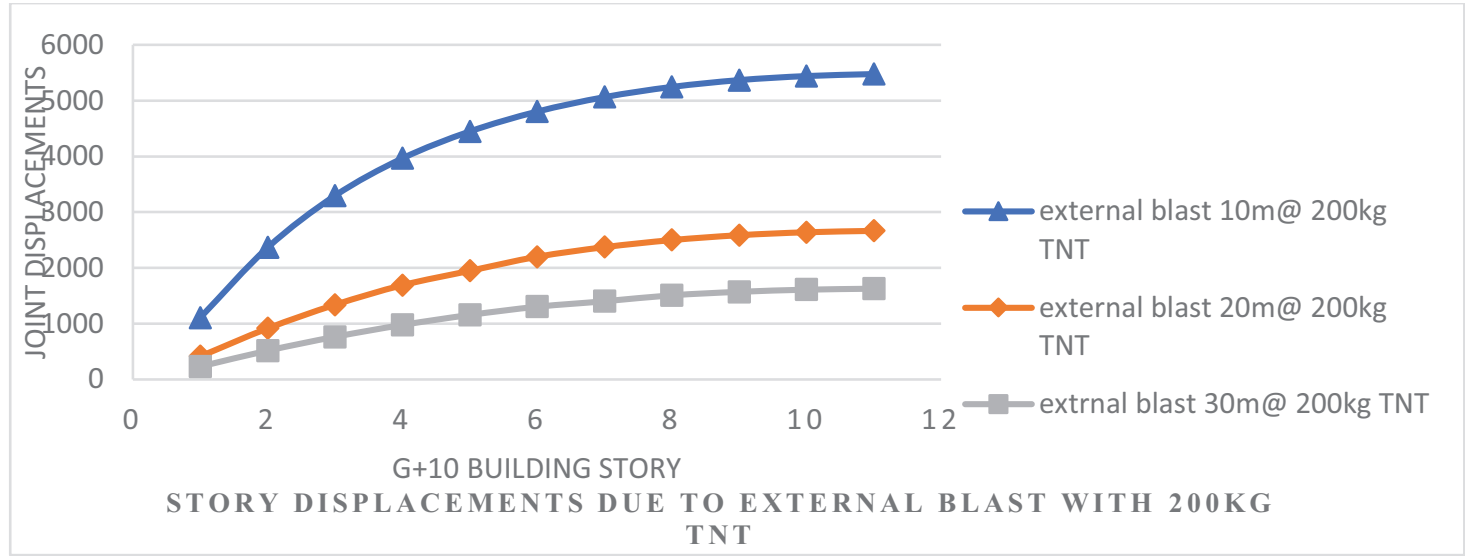

Figure 5.5. Combined graphs charts of storey displacements in UY - direction in external blast charge weight of 200Kg TNT with different standoff distances

As shown in Figure 5.5, framed structure variations of displacement (units: $\mathrm{mm}$ ) graphs with respect to storey height at different stand-off distance as $10 \mathrm{~m}, 20 \mathrm{~m}$ and $30 \mathrm{~m}$ in external blast charge weight of $200 \mathrm{Kg}$ TNT

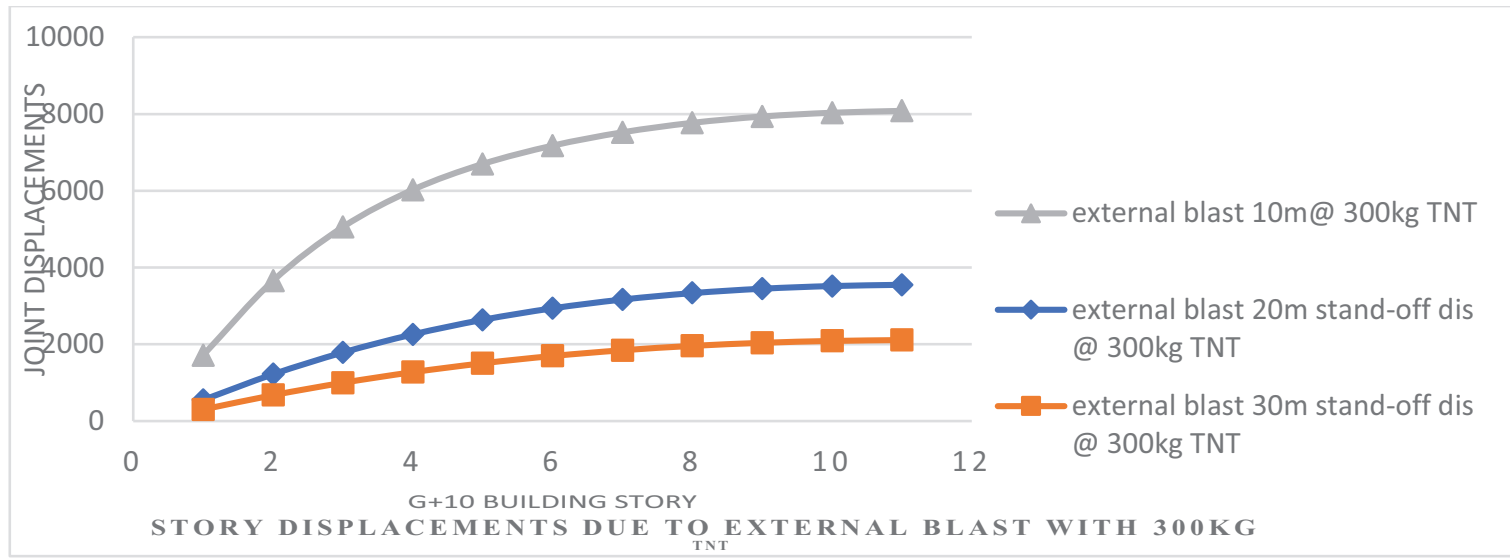

Figure 5.6. Combined graphs charts of storey displacements in UY - direction in external blast charge weight of 300Kg TNT with different standoff distances

As shown in Figure 5.6, framed structure variation of displacement (units: $\mathrm{mm}$ ) graphs with respect to storey height at different stand-off distance as $10 \mathrm{~m}, 20 \mathrm{~m}$ and $30 \mathrm{~m}$ in external blast charge weight of $300 \mathrm{Kg}$ TNT 


\section{G. Shear wall}

It is a structural system composed of braced panels to counter the consequences of lateral load appearing on a structure. [11]

Section property of shear wall

1. Reinforced Concrete shear wall Thickness- $150 \mathrm{~mm}$ Material property of shear wall

1. Material property of shear wall (concrete) M20

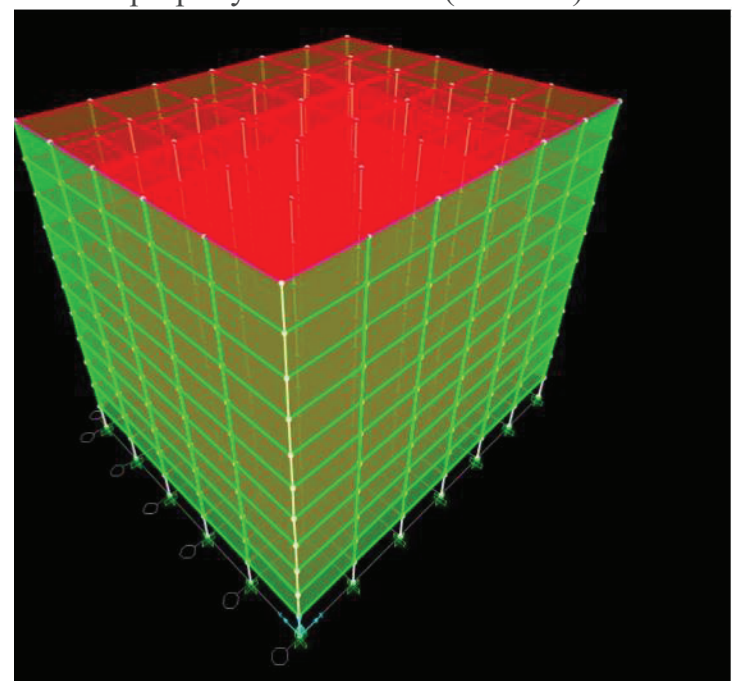

Figure 5.7. G+10 storey building with reinforced concrete external shear walls
The blast load with same intensity and standoff distance is applied with respect to beam column joint structure with external concrete shear walls as shown in Fig 5.7 design Rule's setup in finite element software SAP2000 we get detail Report in displacement and story drift of RCC building.

Similarly blast load is calculated for different charge weights of $100 \mathrm{~kg}, 200 \mathrm{~kg}$ and $300 \mathrm{~kg}$ TNT at stand-off distance $10 \mathrm{~m}, 20 \mathrm{~m}$ and $30 \mathrm{~m}$

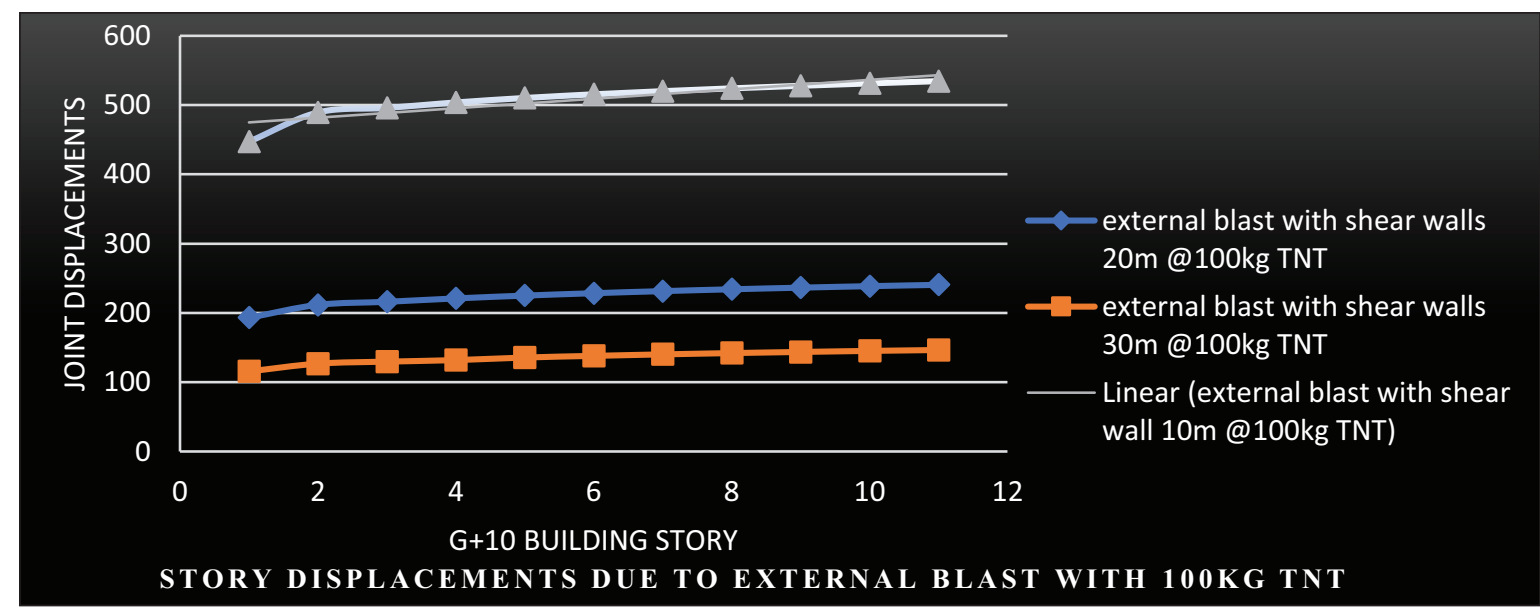

Figure 5.8. Combined graphs charts of storey displacements in UY - direction with shear walls in external blast charge weight of $100 \mathrm{Kg}$ TNT with different standoff distances

As shown in Figure 5.8, framed structure with shear walls variation of displacement (units: $\mathrm{mm}$ ) graphs with respect to storey height at different stand-off distance as $10 \mathrm{~m}, 20 \mathrm{~m}$ and $30 \mathrm{~m}$ in external blast charge weight of $100 \mathrm{Kg}$ TNT 


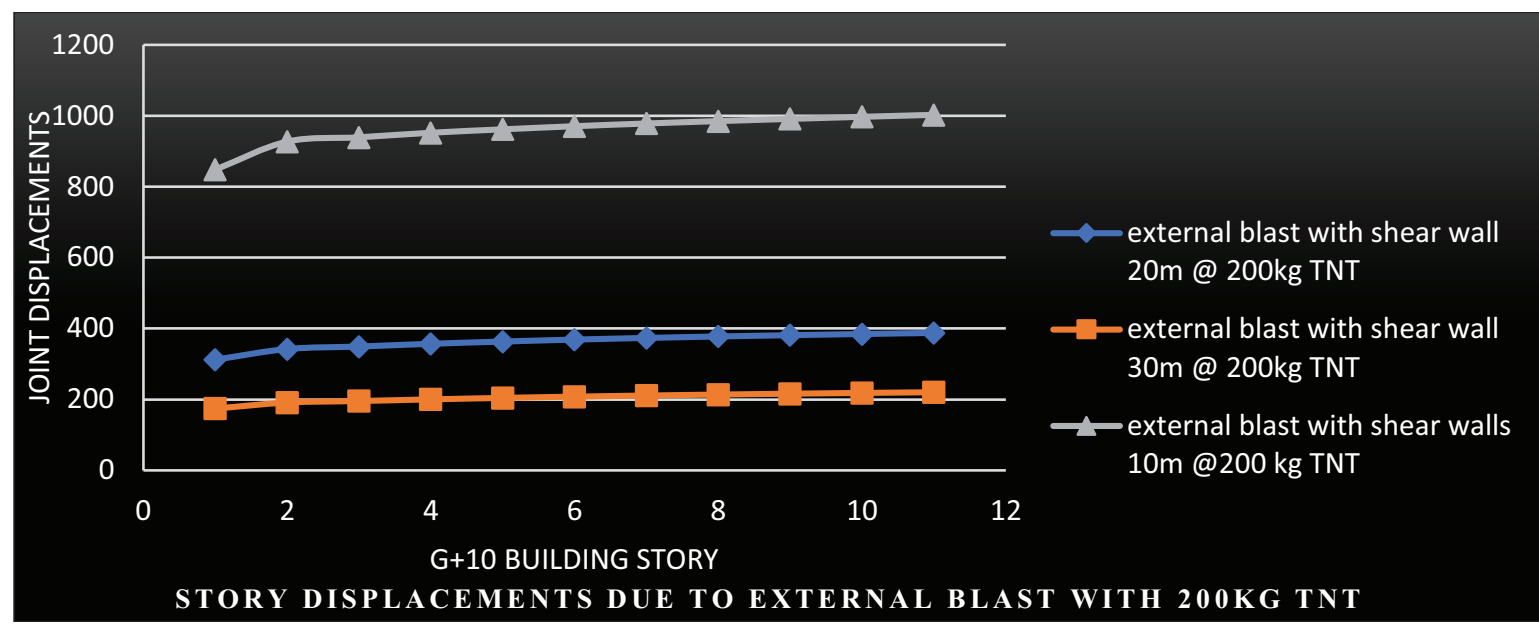

Figure 5.9. Combined graphs charts of storey displacements in UY - direction with shear walls in external blast charge weight of 200Kg TNT with different standoff distances

As shown in Figure 5.9, framed structure with shear walls variation of displacement (units: mm) graphs with respect to storey height at different stand-off distance as $10 \mathrm{~m}, 20 \mathrm{~m}$ and $30 \mathrm{~m}$ in external blast charge weight of $200 \mathrm{Kg}$ TNT

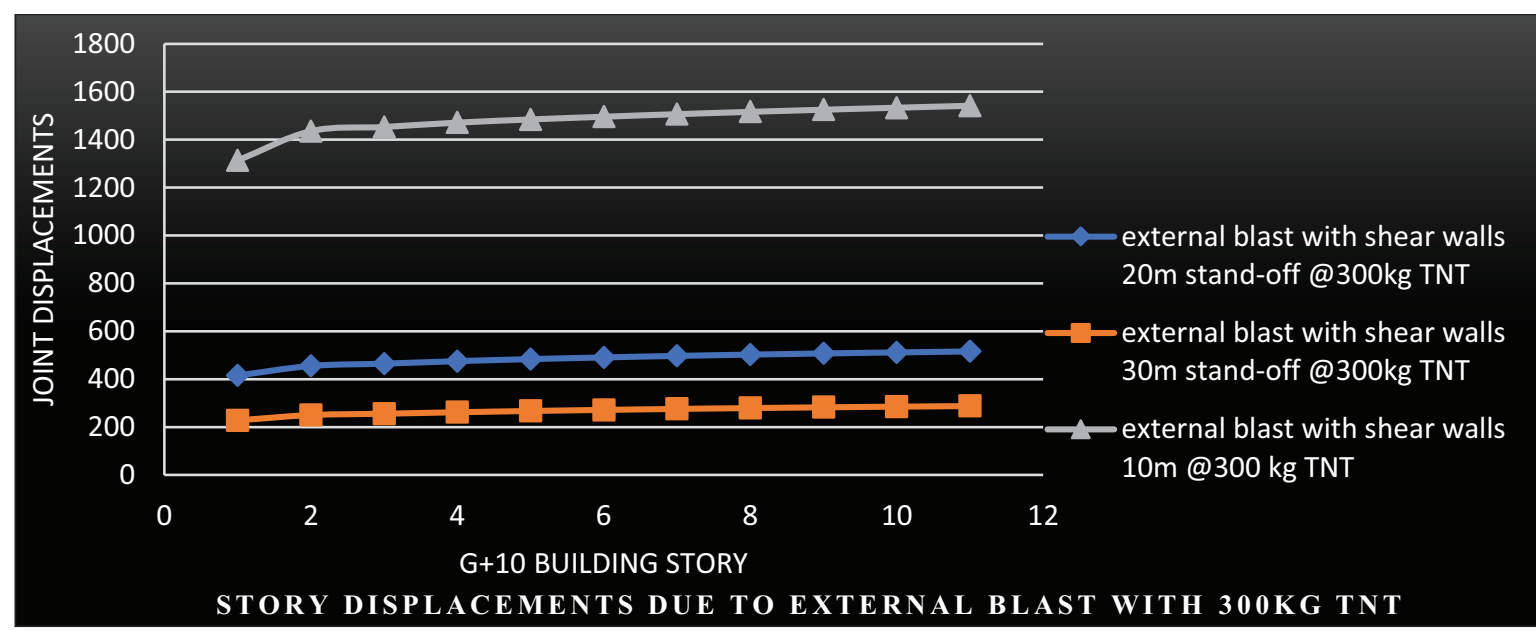

Figure 5.10. Combined graphs charts of storey displacements in UY - direction with shear walls in external blast charge weight of 300Kg TNT with different standoff distances

As shown in Fig. 5.10, framed structure with shear walls variation of displacement (units: mm) graphs with respect to storey height at different stand-off distance as $10 \mathrm{~m}, 20 \mathrm{~m}$ and $30 \mathrm{~m}$ in external blast charge weight of $300 \mathrm{Kg}$ TNT

\section{NON - LINEAR DYNAMIC ANALYSIS}

Non-linear analysis is an analysis where a nonlinear relation holds between displacement and time. This is opposed to linear static analysis. When a blast force is exposed to structure with respect to time, the change of the output is not proportional to the change of the input. [8]

Time history analysis is used to determine the blast response structure under powerful stacking. Time history investigation is a stage through advance assessment of the dynamic reaction of a structure to a focused-on stacking that may likewise vary with time. [8]

A structure subjected to an external explosion; the fundamental natural period of the structure introductory positive pressure stage followed by a negative stage at any point as shown in Figure 6.1. The impact wave is going through a blast wind causing dynamic pressures. If the period of the positive segment, then it offers with an impulsive loading as shown in Figure 6.2. [8]

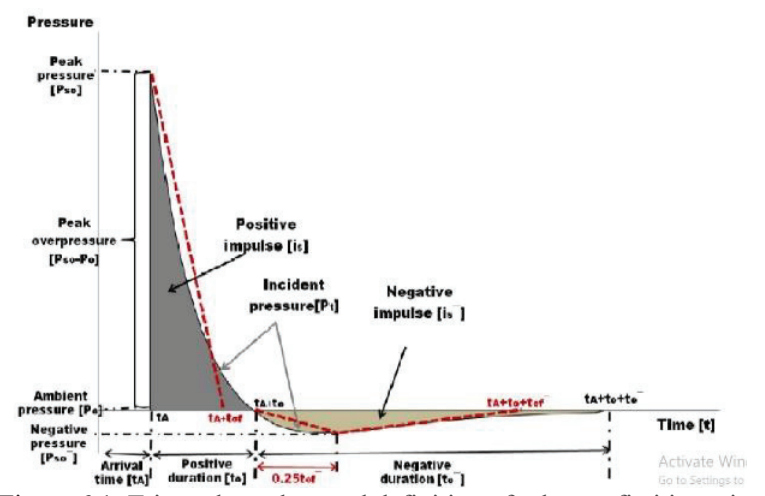

Figure 6.1. Triangular pulses and definition of relevant fictitious times [12] 


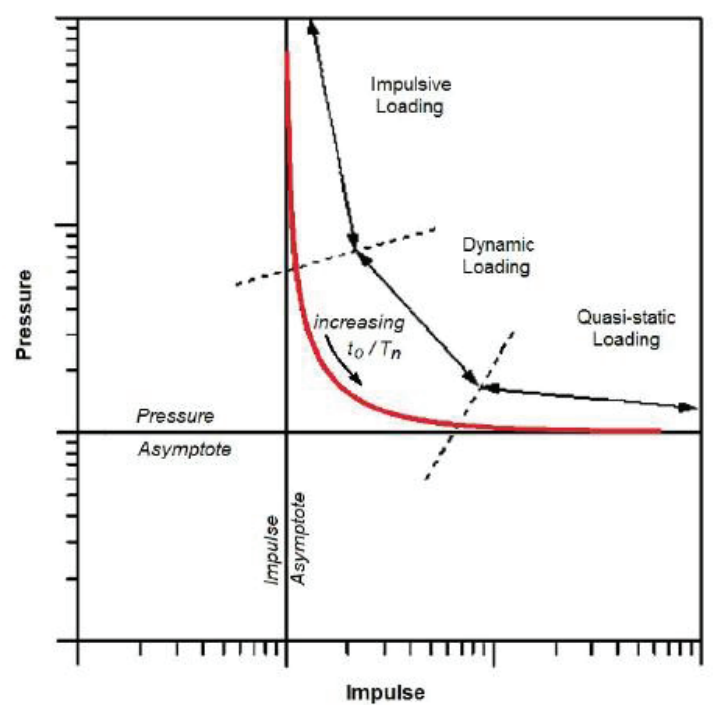

Figure 6.2. Pressure - Impulse diagram. [12]

A G+10 storey RCC commercial building is subjected to $100 \mathrm{~kg}$ Trinitrotoluene (TNT) blast source at the central point of the structure at the ground level was considered throughout the external surface of the building, at a stand-off distance $10 \mathrm{~m}$.

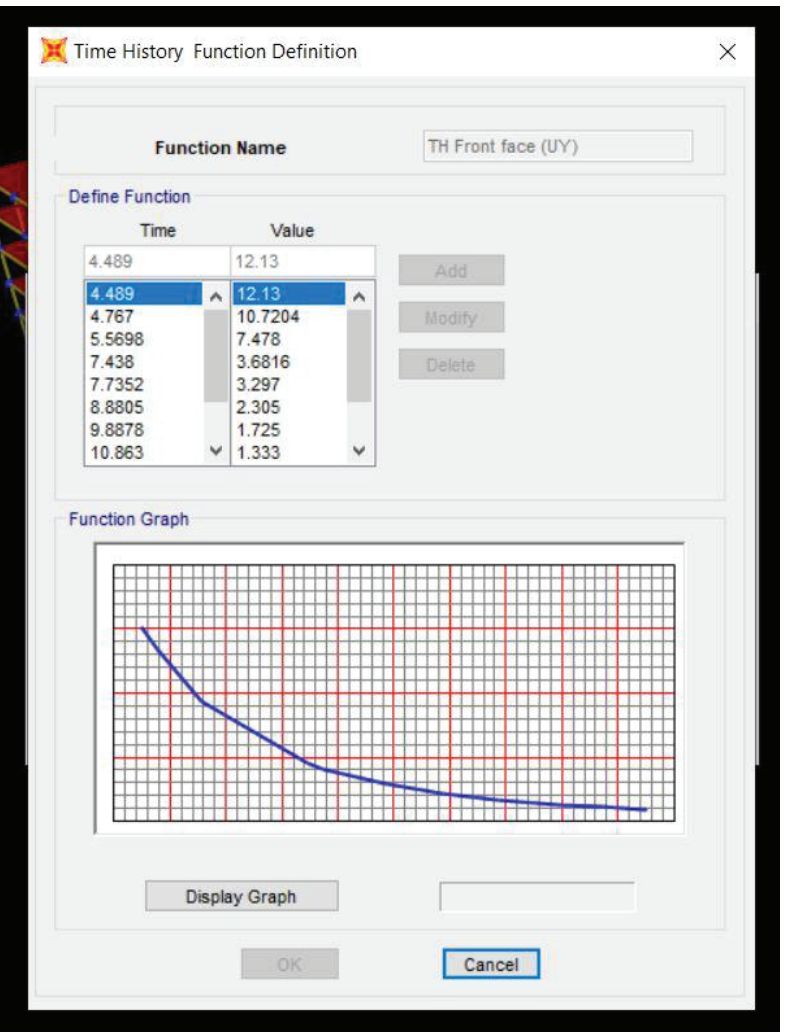

Figure 6.3. Front Face graph Pressure and time of Explosion in time history function

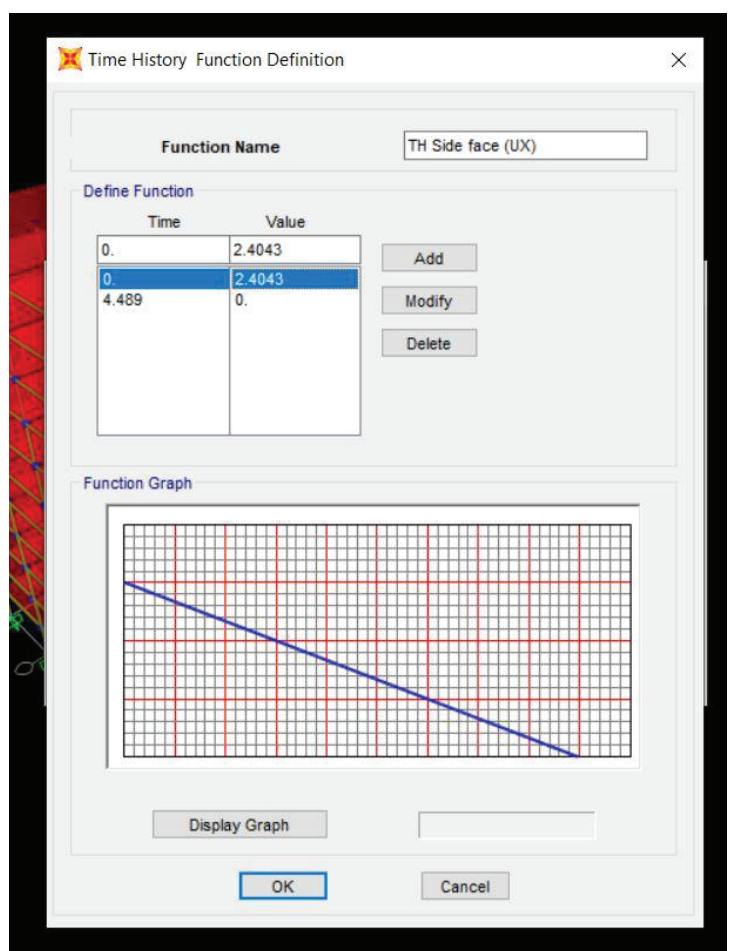

Figure 6.4. Rare Face graph Pressure and time of Explosion in time history function 


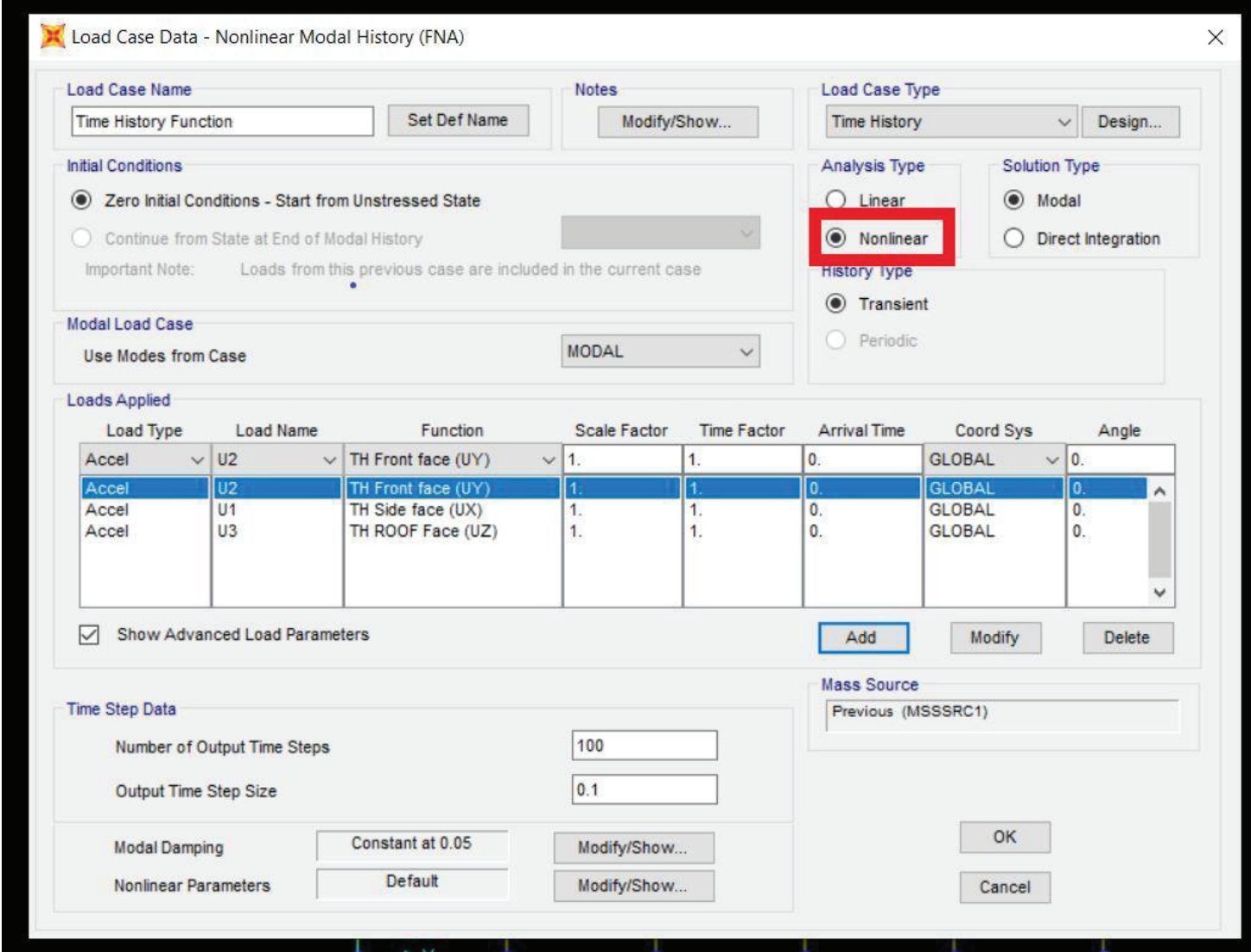

Figure 6.5. Time history analysis by non-linearity

\section{A. Output curves - time history function analysis}

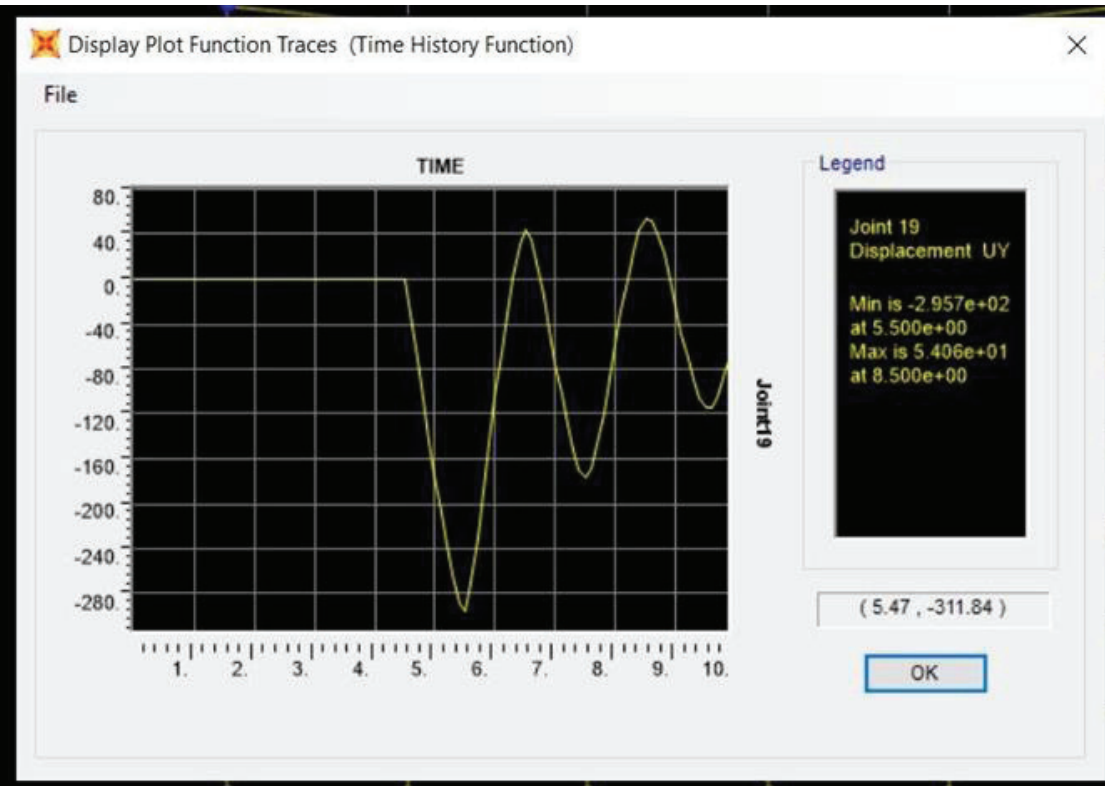

Figure 6.6. Plot function Displacement vs Time 


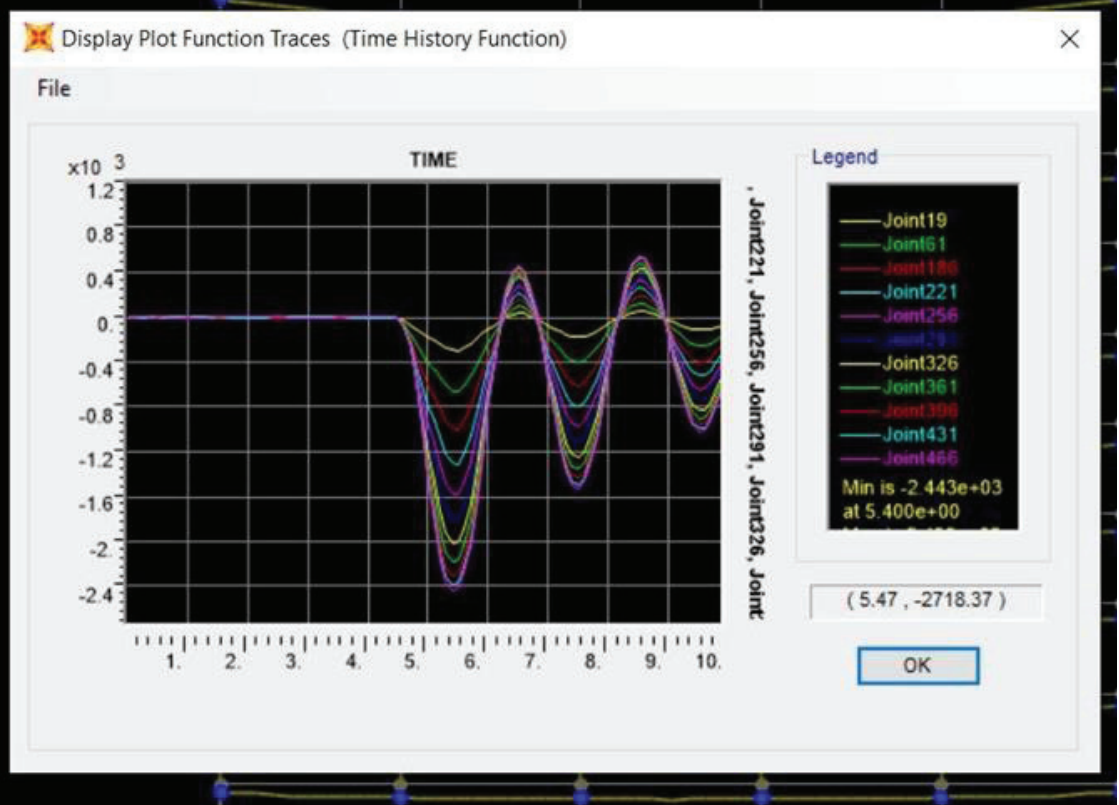

Figure 6.7. Nodal Displacements on the front middle structure vertical

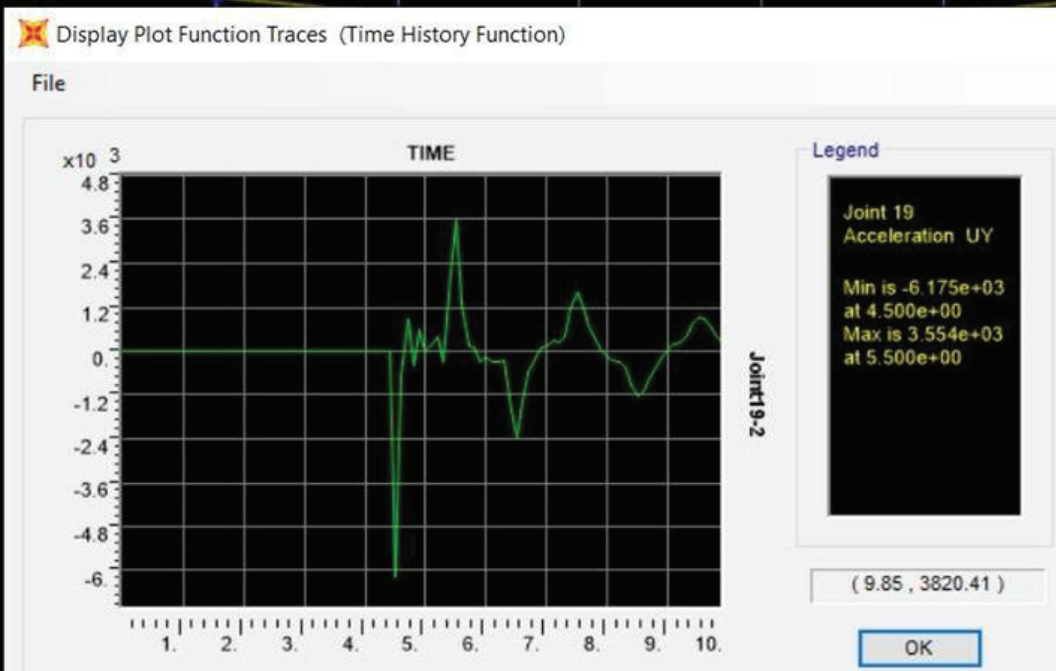

Figure 6.8. Plot function of Acceleration vs Time 


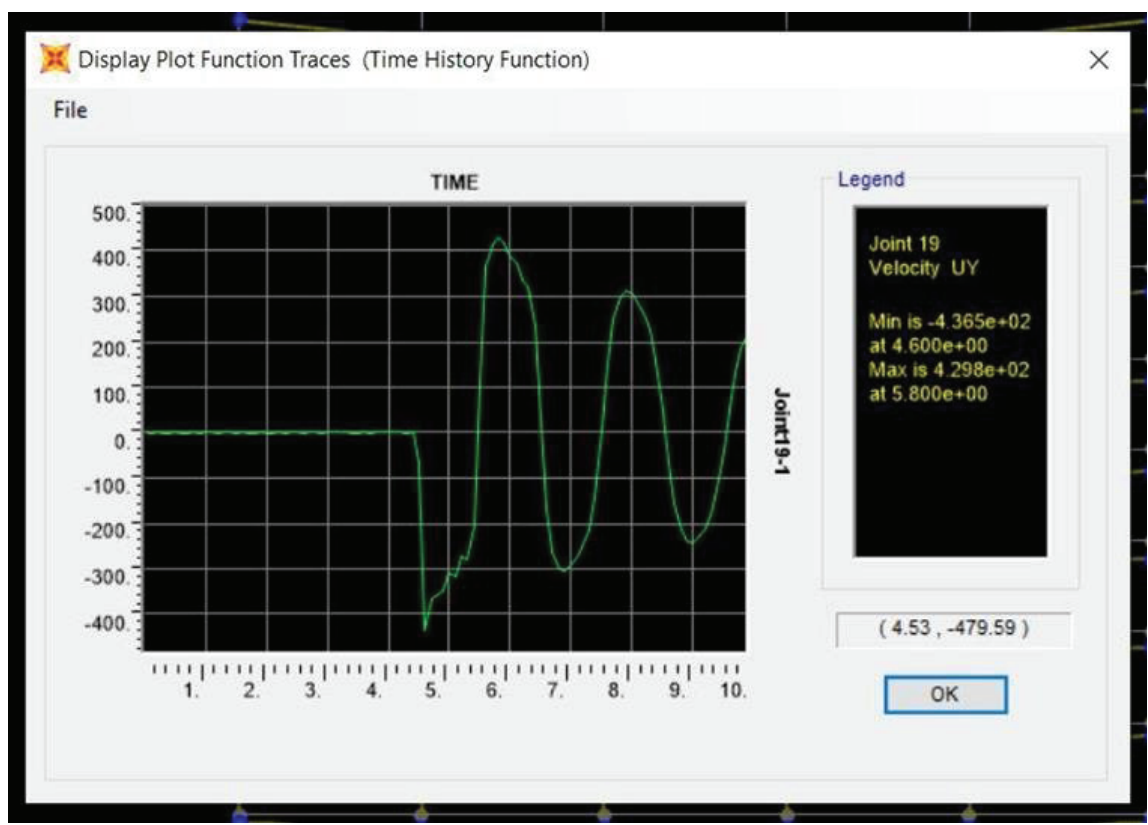

Figure 6.9. Plot function of Velocity vs Time

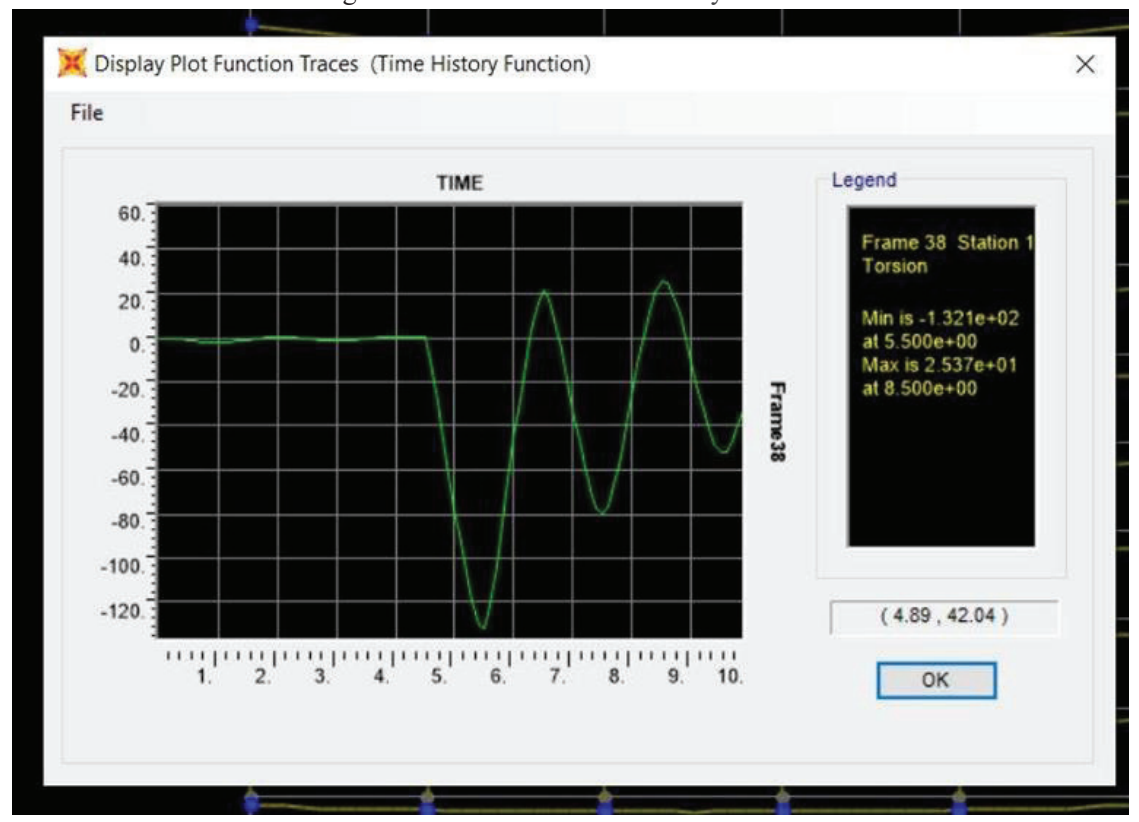

Figure 6.10. Plot function of Torsion vs Time

\section{RESULTS AND DISCUSSIONS}

A G+10 RCC structure is subjected to external blast at $10 \mathrm{~m}, 20 \mathrm{~m}$, and $30 \mathrm{~m}$ stand-off distances and charge weight about $100 \mathrm{kgs}$ TNT blast load in each case is calculated from IS 4991-1968 by this highest lateral displacement is $3089 \mathrm{~mm}, 1680 \mathrm{~mm}$, and $1092 \mathrm{~mm}$

Similarly, building is designed with shear walls of $150 \mathrm{~mm}$ thickness external surface of building with same impact structure is subjected to external blast of $100 \mathrm{~kg}$ TNT at a standoff distances $10 \mathrm{~m}, 20 \mathrm{~m}$, and $30 \mathrm{~m}$ where highest lateral displacement is $534 \mathrm{~mm}, 240 \mathrm{~mm}$, and $146 \mathrm{~mm}$ displacement was decreased about $82 \%, 85 \%$, and $86 \%$
> Again G+10 RCC structure is subjected to external blast at $10 \mathrm{~m}, 20 \mathrm{~m}$, and $30 \mathrm{~m}$ stand-off distances and charge weight about $200 \mathrm{kgs}$ blast load in each case is calculated from IS 4991-1968 by this highest lateral displacement is $5475 \mathrm{~mm}, 2664 \mathrm{~mm}$, and $1627 \mathrm{~mm}$

Similarly, building is designed with shear walls of $150 \mathrm{~mm}$ thickness external surface of building with same impact structure is subjected to external blast of $200 \mathrm{~kg}$ TNT at a standoff distances $10 \mathrm{~m}, 20 \mathrm{~m}$, and $30 \mathrm{~m}$ where highest lateral displacement is $1002 \mathrm{~mm}, 387 \mathrm{~mm}$, and $220 \mathrm{~mm}$ displacement was decreased about $81 \%, 85 \%$, and $86 \%$

Again G+10 RCC structure is subjected to external blast at $10 \mathrm{~m}, 20 \mathrm{~m}$, and $30 \mathrm{~m}$ stand-off distances and charge weight about $300 \mathrm{kgs}$ blast load in each case is calculated 
from IS 4991-1968 by this highest lateral displacement is $8080 \mathrm{~mm}, 3549 \mathrm{~mm}$, and $2110 \mathrm{~mm}$

Similarly, building is designed with shear walls of $150 \mathrm{~mm}$ thickness external surface of building with same impact structure is subjected to external blast of $300 \mathrm{~kg}$ TNT at a standoff distances $10 \mathrm{~m}, 20 \mathrm{~m}$, and $30 \mathrm{~m}$ where highest lateral displacement is $1541 \mathrm{~mm}, 515 \mathrm{~mm}$, and $287 \mathrm{~mm}$ displacement was decreased about $80 \%, 85 \%$, and $86 \%$

\section{Conclusions}

In present study a R.C.C structure was analyzed for blast load in different parametric conditions. When the blast load hits to structure, the blast pressure leads to an increase in the kinetic energy of the structural system. The increase in velocity results in a large displacement of the framed elements.

Variation of displacement is Non-Uniform along the height of building and reached to Collapse Point for minimum standoff distance.

Effects of blast loads can also be decreased by providing lateral moment resisting frames like shear wall

\section{REFERENCES}

[1] IS 4991:1968, Criteria for blast resistant design of structures for explosions above ground

[2] Suraj D Bhosale, Shrinivas.R.Survanshi, "Dynamic analysis of RCC frame structure subjected to blast loading without infilled wall in multi storey building", International Journal of Current Engineering and Technology, Vol.6, No.3 (June 2016)

[3] P. Srinivasa Rao, P. Manoj Kumar, G. Tirupathi Naidu, "Study the impact of blast load on G+7 multistoried RCC structure with varied distances", (IJITEE), ISSN: 2278-3075, Volume-8 Issue-4, February 2019

[4] Nitesh N. moon, "Prediction of blast loading and its impact on buildings", NIT Rourkela, 2009

[5] Ashish Kumar Tiwari, "Analysis of structural response under blast loading using sap - 2000 and autodyn", Jaypee University of Information and Technology Waknaghat Solan, 2015

[6] M. Meghanadh, T. Reshma, "Blast analysis and blast resistant design of R.C.C residential building”, (IJCIET) Volume 8, Issue 3, March 2017

[7] Quazi Kashif, Dr. M. B. Varma, "Effect of blast on g+4 RCC frame structure", IJETAC, ISSN 2250-2459, ISO 9001:2008 Certified Journal, Volume 4, Issue 11, November 2014

[8] Priyanka A., Rajeeva S. V., "Dynamic response of a multi-story building under blast load", The International Reviewer Volume 2 Issue 1 January - June 2015 pp. 17-20 ISSN 2395-1575

[9] Thejashwini, Dr. M N Hegde, "Effect of blast loads on multistoried RCC building", (IRJET), Volume: 05 Issue: 07 July 2018
[10] A. Lalitha, V. Lakshmi, "Analysis of $\mathrm{g}+5 \mathrm{RC}$ building for blast forces”, (IJSR), ISSN: 2319-7064 (2018)

[11] Kanchan Pujari, Prof. D.H. Tupe, Prof. Dr. G.R. Gandhe, "Response of a rectangular reinforced concrete structure with and without shear walls under blast loadings", (IRJET), e-ISSN: 2395-0056 Volume: 06 Issue: 05 May 2019

[12] Vasilis KARLOS, George SOLOMOS, "Calculation of blast loads for application to structural components", Luxembourg: Publications Office of the European Union, 2013 